Article

\title{
Preparation and Characterization of Ultrasound Treated Polyvinyl Alcohol/Chitosan/DMC Antimicrobial Films
}

\author{
Rui Li ${ }^{1,+}$, Yue Wang ${ }^{2,+}$, Jie Xu ${ }^{1}$, Saeed Ahmed ${ }^{1}$ and Yaowen Liu ${ }^{1,2,3, *}$ \\ 1 College of Food Science, Sichuan Agricultural University, Yaan 625014, China; liruilruii@163.com (R.L.); \\ xvjie715@163.com (J.X.); saeedahmed_mahar@yahoo.com (S.A.) \\ 2 School of Materials Science and Engineering, Southwest Jiaotong University, Chengdu 610031, China; \\ yueerjiejie520@163.com \\ 3 California NanoSystems Institute, University of California, Los Angeles, CA 90095, USA \\ * Correspondence: lyw@my.swjtu.edu.cn; Tel./Fax: +86-0835-288-3219 \\ + These authors contributed equally to the work.
}

Received: 8 August 2019; Accepted: 12 September 2019; Published: 15 September 2019

\begin{abstract}
In this research, chitosan (CS) and poly (vinyl alcohol) (PVA) were adopted as a material, methacryloyloxyethyl trimethyl ammonium chloride (DMC) was added in various concentrations and was treated ultrasonically for the formation of films with the use of the polymer blending method. The influences exerted by the ultrasonication period on PVA/CS/DMC antimicrobial active materials underwent material characteristic tests. The consequences revealed that at the break of the compound films, ultrasonication raised the elongation and tensile strength on the whole. Ultrasonication further or also enhanced the light transmittance performance and composite films' barrier property. Furthermore, the compound film with a DMC concentration of $2 \%$ had good antibacterial properties, the film's inhibition rates against Staphylococcus aureus and Escherichia coli after ultrasonication were $79.23 \% \pm 1.92 \%$ and $72.31 \% \pm 1.35 \%$, respectively.
\end{abstract}

Keywords: polyvinyl alcohol; chitosan; methacryloyloxyethyl trimethyl ammonium chloride

\section{Introduction}

Over the years, health-related food packaging has attracted people's attention [1,2]. First, most of the food packaging materials that circulate commercially are petrochemical polymers not capable of being decomposed by bacteria, affecting physical safety and marine circumstance [3]. In addition, most food packaging cannot keep food fresh, which can be unhealthy [4]. Thus, it is particularly important to research a safe, cheap, antimicrobial, and biodegradable polymer film as a food packing material. Among all of the degradable polymers, poly (vinyl alcohol) (PVA) and Chitosan (CS) have aroused rising interest for their film-forming properties and prominent biocompatibility $[5,6]$.

Many studies have already explored the composite films' antimicrobial nature [7]. CS is a unique polysaccharide isolated from crustacean wastes, showing a broad application in food preservation [8]. CS has good film-forming capacity and barrier properties. Furthermore, CS is highly antimicrobial against pathogenic and spoilage microbes (e.g., Gram-negative and bacteria Gram-positive bacteria).

Nevertheless, the mechanical properties of pure CS are weak. It can only be dissolved in acidic media and loses its antibacterial activity at $\mathrm{pH}>6.5$ [9]. The most effective way to address these shortcomings is to mix CS with other polymers (e.g., gelatin) [10], polylactic acid (PLA) [11], poly (vinyl alcohol) (PVA) [12]). PVA refers to a non-toxic synthetic polymer with prominent solubility and film-forming nature. PVA film exhibits high strength, non-toxicity, and is acid and alkali resistant [13]. Due to the compatibility of PVA, CS can be repaired by the hydrogen bond structure 
to enhance the mechanical properties of CS [14]. Many existing studies have used physical and chemical approaches for preparing PVA/CS composite membranes (e.g., polymer blending, chemical modification, graft copolymerization and crosslinking) [15]. To be specific, polymer blending is an easy-to-achieve and feasible approach extensively adopted for preparing PVA/CS composite films. The mixing of chitosan and PVA is advantageous because both of them are polar materials with considerable hydroxyl categories in their chemical structure. The mentioned polar hydroxyl groups often form intermolecular and intramolecular hydrogen bonds. Hydrogen bonds formed between chitosan and polyvinyl alcohol are beneficial in promoting the local stability of chitosan and polyvinyl alcohol, and thus improving the miscibility of chitosan and polyvinyl alcohol [16]. The influences exerted by different plasticizers on various biopolymers have been explored [17]. Nevertheless, the moisture barrier of the film is likely to be decreased by the hydrophilicity of hydroxyl groups on PVA and amine groups on CS. Reactive monomers with vinyl and quaternary ammonium functional groups (e.g., 2-[(methacryloyloxy) ethyl] trimethylammonium chloride) can be copolymerized by self-polymerization or with other unsaturated monomers for the formation of multiple functionalities. With the material and the presence of quaternary ammonium salt groups, the entire functional material molecule exhibits cationic properties. Of all cationic monomers, 2-[(methacryloyloxy) ethyl] trimethylammonium chloride (DMC) refers to the industrial comonomers with the highest popularity used with acrylamide as flocculants [18-21]. In existing studies, 2-[(methacryloyloxy) ethyl] trimethylammonium chloride (DMC) has been the monomer analyzed and employed for producing polysaccharide-based flocculants to treat effluents $[19,22]$. Furthermore, chitosan was reported to be modified for producing flocculant [23,24].

This study aimed at studying PVA/CS/DMC blend films' antibacterial, physical, and structural natures. With the use of Fourier transform infrared (FTIR) spectroscopy, we described the characteristics of the films. Light transmission, water vapor permeability (WVP), and mechanical properties were studied as well. We assessed the antimicrobial activity against Gram-positive (Staphylococcus aureus) bacteria and Gram-negative (Escherichia coli). To more quickly extract DMC and accelerate its dissolution, ultrasonication was applied to mix DMC, PVA, and CS. Then, we explored the intermolecular interactions. These results are added to the literature because the results stress the role of ultrasonication to potentiate the properties of active packaging materials.

\section{Materials and Methods}

\subsection{Materials}

Shandong Aokang Biotech Ltd (Jinan, China) provided Chitosan of $90 \%$ deacetylation degree and molecular weight $(\mathrm{Mw})$ of $2.8 \times 10^{5}$. Acetic acid $(2 \%, v / v)$ (Junsei, Tokyo, Japan) was employed to dissolve CS. Wuxi Beinuo Biological Technology (Jiangsu, China) provided PVA (Mw $=7.6 \mathrm{kDa}$, $\mathrm{Mw} / \mathrm{Mn}=1.32$ ) powders. Guoling Instrument, Inc. (Wuhan, China) provided acetic acid (glacial 100\%, water solution). Other chemicals belong to analytical grade, and they were used as acquired. Chengdu Kelong Reagent Co. (Chengdu, China) provided E. coli and S. aureus, unless otherwise stated. DMC was provided by Wuxi XinYu Chemical Technology (Jiangsu, China).

\section{2. $P V A / C S$ and $P V A / C S / D M C$ Films Preparation}

Figure 1 shows we fabricated PVA/CS/DMC and PVA/CS composites by blending the different components together. Solutions of 10\% $(w / v)$ PVA and 3\% $(w / v)$ CS were resolved in the same acetic acid solution volume separately $(2 \%, v / v)$. To form a homogenous PVA/CS solution with the volumetric proportion of 1:1, the CS solution and PVA solution were mixed and stirred for $0.5 \mathrm{~h}$. DMC $(2,4,6,8 \mathrm{~g})$ solutions with different quantities were dropped into PVA/CS solution and energetically stirred for $24 \mathrm{~h}$ using a magnetic stirrer to ensure mixed homogeneity [25]. Glycerol $(2 \mathrm{~mL}$ per $200 \mathrm{~mL}$ of film-forming solution) was used as a plasticizer. The consistent solutions were kept at about $25{ }^{\circ} \mathrm{C}$ for $24 \mathrm{~h}$ to take away bubbles forming throughout stirring. To detect the influence exerted by ultrasonication on 
film-forming performance, each solution was subjected to ultrasound in the ultrasonic limpid cav at an ultrasonic frequency of $40 \mathrm{kHz}$ and power of $50 \mathrm{~W}$ [26]. PVA/CS/DMC blend film was planned as a composite film using a slight layer of a homogeneous blend on a Teflon pane. Subsequently, we incubated the composite film in an oven for $24 \mathrm{~h}$ at $40^{\circ} \mathrm{C}$ to remove solvents; then we placed it in a vacuum oven for $24 \mathrm{~h}$ at $40{ }^{\circ} \mathrm{C}$ to remove all remainders. Blend films of PVA/CS/DMC at different concentrations were acquired (Table 1 ) and stored in a desiccator.

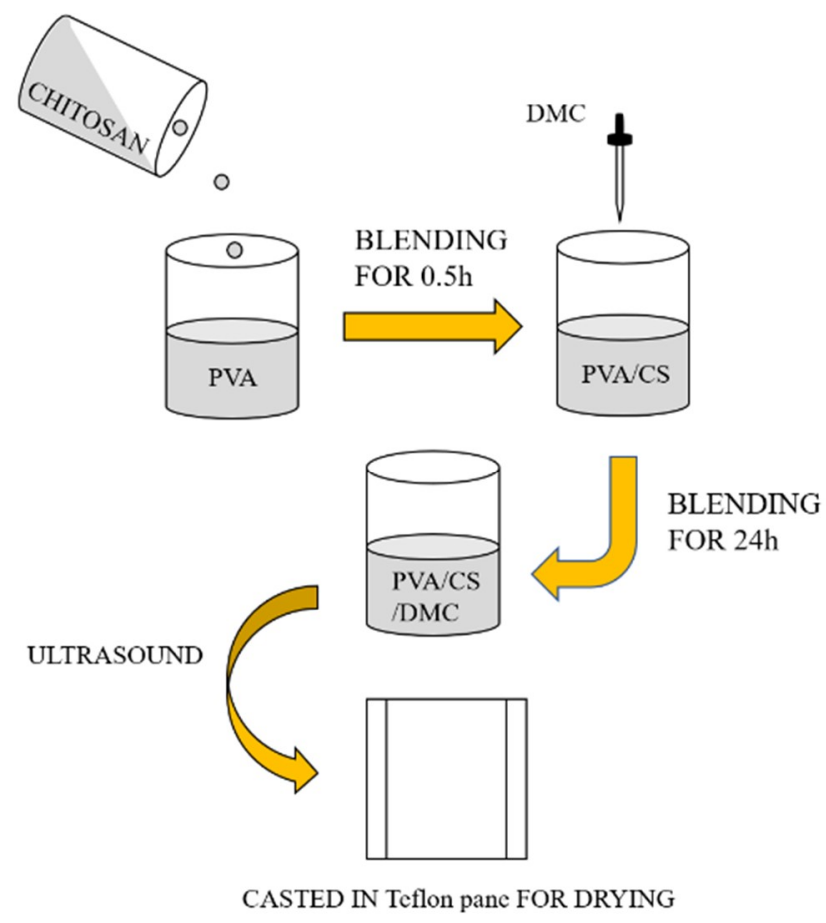

Figure 1. Schematic illustration of the poly (vinyl alcohol)/chitosan/2-[(methacryloyloxy) ethyl] trimethylammonium chloride (PVA/CS/DMC) blend films' fabrication process.

Table 1. Sample codes and composition for the poly (vinyl alcohol)/chitosan/2-[(methacryloyloxy) ethyl] trimethylammonium chloride (PVA/CS/DMC) film-forming solutions.

\begin{tabular}{ccccc}
\hline Sample & DMC (g) & CS (g) & PVA (g) & Gly (g) \\
\hline PVA & 0 & 0 & 26 & 2 \\
PVA/CS & 0 & 6 & 20 & 2 \\
PVA/CS/DMC-1\% & 2 & 6 & 20 & 2 \\
PVA/CS/DMC-2\% & 4 & 6 & 20 & 2 \\
PVA/CS/DMC-3\% & 6 & 6 & 20 & 2 \\
PVA/CS/DMC-4\% & 8 & 6 & 20 & 2 \\
\hline
\end{tabular}

\subsection{Fourier-Transform Infrared Experiment}

For the identification of the chemical constitutions of the potential interactions and the PVA/CS/DMC composite films between their compositions, we used attenuated total reflectance Fourier-transform infrared (ATR-FTIR, Bruker Gmbh, Ettlingen, Germany) spectrometry. We employed a small-scale slice split from every composite film. We explored the samples with 100 total scans per sample, the sample scan time of $32 \mathrm{~s}$, the background scan time of $32 \mathrm{~s}$, scanner velocity of $2.2 \mathrm{kHz}$, an aperture setting of $6 \mathrm{~mm}$, the range of 650 to $4000 \mathrm{~cm}^{-1}$ and a resolution of $4 \mathrm{~cm}^{-1}$, in the range of 650 to $4000 \mathrm{~cm}^{-1}$. With the use of a Bruker 66 spectrometer (Ettlingen, Germany), in the absorbance mode, we recorded spectral outputs as a wave number function [26]. 


\subsection{Thickness}

With the use of a handheld micrometer (Tactix 245311, Meridian International Co. Ltd, Shanghai, China), the film thickness was measured to the nearest $0.01 \mathrm{~mm}$. We performed measurements in at least seven random locations of every film preconditioned, of which the values were expressed as mean \pm standard deviation (SD). For determining opacity, mechanical properties, and water vapor permeability (WVP), we employed mean values.

\subsection{Water Vapor Permeability}

Through the measurement of the water vapor transmission rate (WVTR) using the ASTM method E96-00 [26], sample films' water vapor permeability was measured. Such value was ascertained with the technique of Zhang et al. [27]. Over the vial (15 mm diameter) that contains $10 \mathrm{~mL}$ of water, we mounted the films for the measurement of WVTR. Subsequently, with a saturated solution of ammonium sulfate, we placed the vials in a desiccator at $37^{\circ} \mathrm{C}$. We built a weight loss vs. time plot and weighed the assembly at regular intervals. According to the plot's slope, we obtained the WVTR as:

$$
\operatorname{WVTR}\left(\frac{g}{\frac{m^{2}}{d}}\right)=\text { slope } \times 24 / A
$$

where $g$ represents the quality of water vapor per unit area per unit time. $m$ represents the area of the film. $d$ represents a day. $A$ represents the permeation area of the sample $\left(\mathrm{m}^{2}\right)$.

\subsection{Light Transmittance}

In terms of the composite films exhibiting a smooth surface free of damage, light transmittance was gauged. With the technique of Yu et al., we ascertained such value [28]. We split films into strip-like samples, each $10 \mathrm{~mm}$ in width and $50 \mathrm{~mm}$ in length. Then, on a UV-visible spectrophotometer (Shanghai Yuan Analysis Instrument Co., Ltd, Shanghai, China), we placed the samples in close contact with the $1 \mathrm{~cm}$ cuvette inner wall for a light transmittance measurement at $600 \mathrm{~nm}$. A blank cuvette acted as blank control. We performed the measurement in triplicate and took the average values into account here.

\subsection{Color Properties}

With the use of a HunterLab ColorFlex (Xinlian Creation Electronic Co. Ltd., Shanghai, China), we evaluated the color of the films. With the use of the methods of Vaezi et al., we tested the color properties of specimens [29]. We ascertained color values of $L^{*}$ (luminosity), $a^{*}$ (negative-green; positive-red), and $b^{*}$ (negative-blue; positive-yellow). We followed a standard plate, and CX 2064 was adopted as standard [29]. The total color difference $\left(\Delta E^{*}\right)$ was calculated by

$$
\Delta E=\left[(\Delta L)^{2}+\Delta a^{2}+\Delta b^{2}\right]^{0.5}
$$

where $\Delta L=L^{*}$ standard $-L^{*}$ sample, $\Delta a=a^{*}$ standard $-a^{*}$ sample, $\Delta b=b^{*}$ standard $-b^{*}$ sample. The standard plate's color parameter values include $L^{*}=89.05, a^{*}=1.97, b^{*}=-5.96$.

\subsection{Tensile Properties}

With the use of the methods presented by Peng et al. [30], we tested the specimens' tensile strength and breaking elongation rate. Specimens were split to $10 \mathrm{~mm} \times 80 \mathrm{~mm}$ in size and placed using HD-B609B-Stensile tester (Haida International Equipment Co., Ltd., Dongguan, China); we achieved a stretching rate of $250 \mathrm{~mm} / \mathrm{min}$. 


\subsection{Density Test}

The composite film was split into specimens with area (s). A thickness gauge was used to measure the thickness $(d)$, calculated as the average of one point at the center of the specimen and four more spread around with an accuracy of $1 \mu \mathrm{m}$. The mass $(m)$ was ascertained by an electronic scale with an accuracy of $0.1 \mathrm{mg}$; $\mathrm{s}$ is the specimen area; to calculate the film density ( $\rho$ ), Equation (3) was employed. The samples were treated at constant temperature $\left(23^{\circ} \mathrm{C}\right)$ and humidity $(50 \%)$ before testing. For each film specimen, we repeated the above steps 3 times, and we obtained the mean values [31].

$$
\rho=\frac{m}{s \times d}
$$

\subsection{Biodegradability in Soil}

For 30 days, we buried PVA/CS/DMC biodegradable films in the soil. According to the films' weight loss various time, the films' degradation curve can be calculated [32]. We buried the sample into the soil $10 \mathrm{~cm}$ away from the earth's surface. Every 5 days, we removed buried samples from the soil, cleaned them with deionized water, dried them at $60^{\circ} \mathrm{C}$ until the weight of the films did not vary. Sample degradation percentage was calculated by the formula below:

$$
I_{S}(\%)=\left(w-w_{i}\right) / w \times 100
$$

where $I_{S}$ is the degradation percentage. $w$ and $w_{i}$ are the initial weight and the weight at different burial times of the films after being washed and dried.

\subsection{Moisture Content}

Through the measurement of weight loss by drying in an oven at $110^{\circ} \mathrm{C}$ until the sample reached constant weight (dry sample weight), we ascertained the films' water content. We analyzed samples in triplicate. Given the initial weight and the dry weight of each conditioned sample, we obtained equilibrium moisture content (\%) [33].

Then, we ascertained the moisture content in the film by [34]:

$$
\text { Moisture content }(\%)=\frac{\left(M_{i}-M_{t}\right)}{M_{i}} \times 100
$$

where $M_{i}$ and $M_{t}$ presented the weights of film sample before and after drying, respectively.

\subsection{Antimicrobial Experiment}

We tested the composite films with the most prominent whole properties for their bacteriostatic performance applying the colony that counted approach. Escherichia coli (ATCC-25922) and Staphylococcus aureus (ATCC-25923), the Gram-positive bacteria and most typical gram-negative, acted as the exam bacteria, respectively [35]. We split the experimental and constraint group of samples into slices. Next, we weighed and put $1 \mathrm{~g}$ (dry weight) of a sample into Erlenmeyer flasks for high-temperature sterilization. Next, we poured $50 \mathrm{~mL}$ of the NA solutions (NA prepared by $1 \mathrm{~mL}$ nutrient broth $+499 \mathrm{~mL} 0.8 \% \mathrm{NaCl}$ ) into the flasks. We transferred Escherichia coli and Staphylococcus aureus via inoculation loops into the flasks filled with $150 \mathrm{~mL}$ of nutrient broth. The bacteria were incubated at $37^{\circ} \mathrm{C}$ with continuous stirring for $24 \mathrm{~h}$. Subsequently, we injected $1 \mathrm{~mL}$ of the incubated broth medium into two Erlenmeyer flasks, one covering the sample and the other covering NA solution. We incubated the two flasks at $37^{\circ} \mathrm{C}$ for $24 \mathrm{~h}$ while being stirred. Then, we suctioned and uniformly coated $100 \mu \mathrm{L}$ of the incubated sample solution on a solid medium. Next, it was incubated in a constant temperature incubator at $37^{\circ} \mathrm{C}$ for $24 \mathrm{~h}$. Afterward, we removed the 
incubated solid medium and counted the colony. We performed the whole operation under aseptic conditions. We obtained the bacteriostatic rate by:

$$
\text { Bacteriostaticrate }(\%)=\frac{W_{t}-Q_{t}}{W_{t}} \times 100 \%
$$

In the above formula, $W_{t}$ refers to the colony count of a PVA/CS film in the control group, while $Q_{t}$ refers to the colony count of a PVA/CS/DMC composite film in the experimental group.

\subsection{Statistical Analysis}

We tested many samples, with the results expressed as mean \pm standard deviation. We separated the means by Duncan's multiple range test. The obtained values were subjected to analysis of variance (Super ANOVA, Abacus Concepts, Inc., Berkeley, CA, USA), with $p$ values of $<0.05$ considered significant.

\section{Results and Discussion}

\subsection{FTIR Analysis of PVA/CS/DMC Composite Films}

To survey the compatibility and the interactions in the PVA/CS/DMC blend films, FTIR analysis was used [36]. The FTIR spectra of DMC, PVA, CS, and the blend films are demonstrated in Figure 2. In the spectrum of pure CS, the absorption peaks around 1595 and $1654 \mathrm{~cm}^{-1}$ belong to bending and asymmetric stretching of acetamido groups, respectively. CS gave peaks at $3300 \mathrm{~cm}^{-1}$, and $1030 \mathrm{~cm}^{-1}$ representing $\mathrm{OH}$ absorption and glycosidic bond absorption, respectively. In contrast, the characteristic peaks of the pure PVA film embodied a peak belonging to $\mathrm{O}-\mathrm{H}$ and stretched vibration at wavenumber $3300 \mathrm{~cm}^{-1}$, another peak belonging to $\mathrm{CHOH}$ stretched vibration at $1258 \mathrm{~cm}^{-1}$ while other noticeable peaks at 1713 and $1142 \mathrm{~cm}^{-1}$ belong to $\mathrm{C}=\mathrm{O}$ stretching vibration of ester bond and carboxyl $\mathrm{C}=\mathrm{O}$ groups, respectively. The absorption peak at $2941 \mathrm{~cm}^{-1}$ belongs to the bending vibrations of C-H bonds, agreeing with the literature that was previously reported [37]. There was an interaction between CS and PVA, provided the typical peaks of PVA and CS are viewed with a little shift in their frequencies [38]. For all PVA/CS films, the typical bands were similar to those of PVA; strong amorphous carbonyl stretching vibrations of PVA remained constant in all films. The peak intensity grew with raised CS contents. Because of hydrogen bonding between the hydroxyl groups of PVA and hydroxyl or amine groups of CS in the mixed films, the typical figure of the CS spectrum varied, and the peak moved towards a more down frequency range [39]. The FTIR spectrum of the DMC film presented in Figure 2 shows three absorption peaks for the copolymer at 1719, 1456, and $953 \mathrm{~cm}^{-1}$ that are characteristic of the DMC unit and resulting from the ester group, ethylene group, and methyl group of quaternary ammonium in the DMC unit, respectively $[1,18]$. The FTIR spectrum of the PVA/DMC film, shown in Figure 2, compares the infrared spectra for the PVA/DMC composite counterparts and properties in which the PVA films suggested that the addition of DMC down-regulated the intensity of $\mathrm{O}-\mathrm{H}$ absorption peaks, i.e., both inter-PVA and intra-PVA hydrogen bonds were down-regulated by the addition of DMC. The new distinctive bands at $1718 \mathrm{~cm}^{-1}$ that were assigned to the $\mathrm{CO}$ stretching vibration concerning the infrared spectra of PVA/CS/DMC composite films, the hydroxyl-stretching vibration area in the wavenumber scope of 3500 to $3000 \mathrm{~cm}^{-1}$, and the $\mathrm{CO}$ stretching vibration area in the wavenumber scope of 1200 to $1000 \mathrm{~cm}^{-1}$ was comparatively sensitive to compositional alterations in the films. In brief, PVA/CS films revealed that the O-H assimilation peaks moved from $3300 \mathrm{~cm}^{-1}$ in the pure films to $3297 \mathrm{~cm}^{-1}$ in the composite films by ultrasonication comparison of infrared spectra for the PVA/CS/DMC composite counterparts and properties, highlighting the formation of a new hydrogen bond between the DMC and PVA molecules. Both, Siddaramaiah et al. and Kubo et al. confirmed the formation of interacting hydrogen bonds between PVA and substances introduced through their experiments [40,41]. 
Ultrasonic processing, to some extent, impacted the hydrogen bonds formed between the PVA and DMC molecules, as illustrated in Figure 2. The reason for this is probably the cavitation influence of the ultrasonic wave, which could have broken the hydrogen bonds that are constituted between DMC and PVA, thereby releasing the intermolecular hydroxyl groups and improving their absorption peak intensities. Furthermore, the super-mixing influence intensified molecular movement, breaking of hydrogen, and thereby, speeding up the constitution of bonds [41].

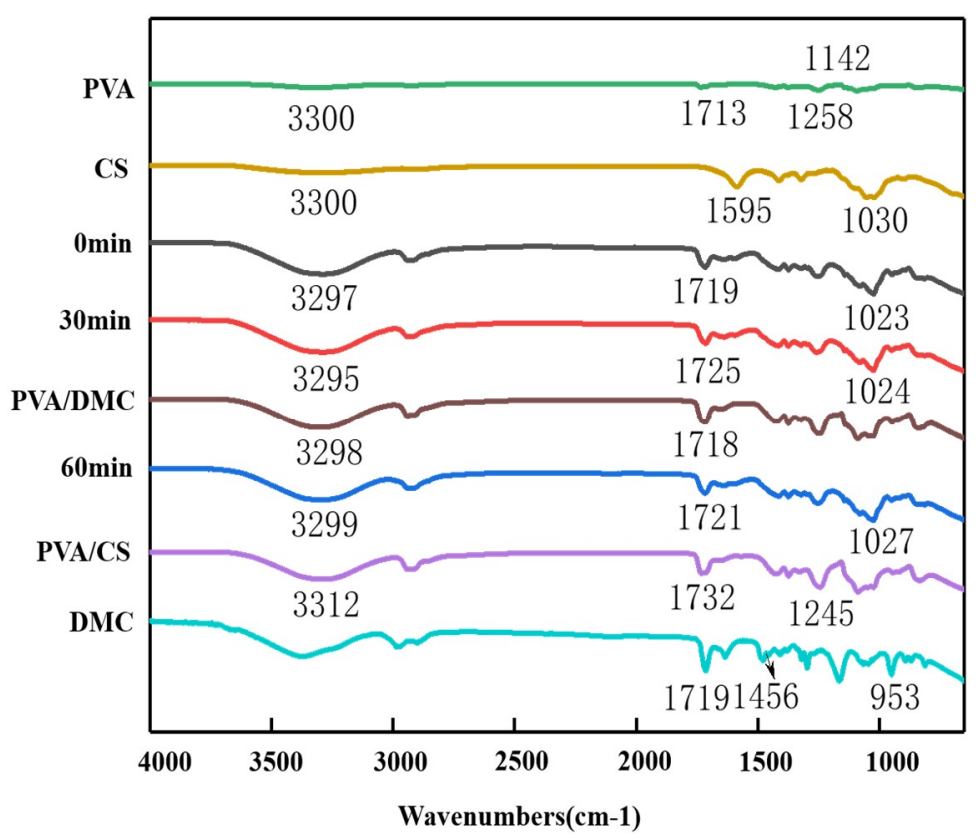

Figure 2. FTIR spectra of the PVA, CS, PVA/CS, PVA/DMC film (not processed with ultrasonication) and typical PVA/CS/DMC composite films with a concentration of $2 \%$ below different ultrasound times.

\subsection{Morphology of PVA/CS/DMC Composite Films}

Morphology of PVA/CS/DMC composite films is shown in Figures 3 and 4. PVA/CS/DMC composite films forming solutions were fabricated using various DMC concentrations. When the solution is dry, the film was easy to remove from the casting vessel. It is suggested that the composite films' solutions were more homogeneous at the concentration of DMC of $2 \%$ and under the ultrasound time of $30 \mathrm{~min}$. PVA/CS/DMC-2-30 min composite films were visually homogeneous, clear, smooth, and flexible. It has been verified that the turbulent effect of ultrasonic cavitation brought about collision and high-speed oscillations of the particles, thus facilitating the interaction between composites and making them disperse more uniformly.

\subsection{Water Vapor Permeability of PVA/CS/DMC Composite Films}

The water vapor loss of PVA/CS/DMC films is presented in Figure 5. The WVTR of PVA/CS-1, PVA/CS-2, PVA/CS-3, and PVA/CS-4 were 0.097, 0.105, 0.131, and $0.136 \mathrm{~g} / \mathrm{m}^{2} /$ day, separately. In the meantime, WVTR of the blank sample acquired from a water-free surface was $0.075 \mathrm{~g} / \mathrm{m}^{2} / \mathrm{day}$. Accordingly, as a composite film, PVA/CS/DMC-1, PVA/CS/DMC-2, PVA/CS/DMC-3, and PVA/CS/ DMC-4 could up-regulate the evaporative water loss by $29.33 \%, 40.00 \%, 74.67 \%$, and $81.33 \%$ to yield a moist environment [42]. Compared with PVA/CS, PVA/CS/DMC-2, PVA/CS/DMC-3, PVA/CS/DMC-4 composite films indicated significantly higher WVP $(p<0.05)$. One is the hydrophilic nature of CS, probably facilitating water molecules' transport via the film [43], and the less crystallinity of composite films exhibiting larger higher CS contents [36]. The other, a more open matrix formation in PVA/CS/DMC composite films, where the polymer chains are packed in a lower dense manner attributed to the more extensive hydration layers of CS [27]. 


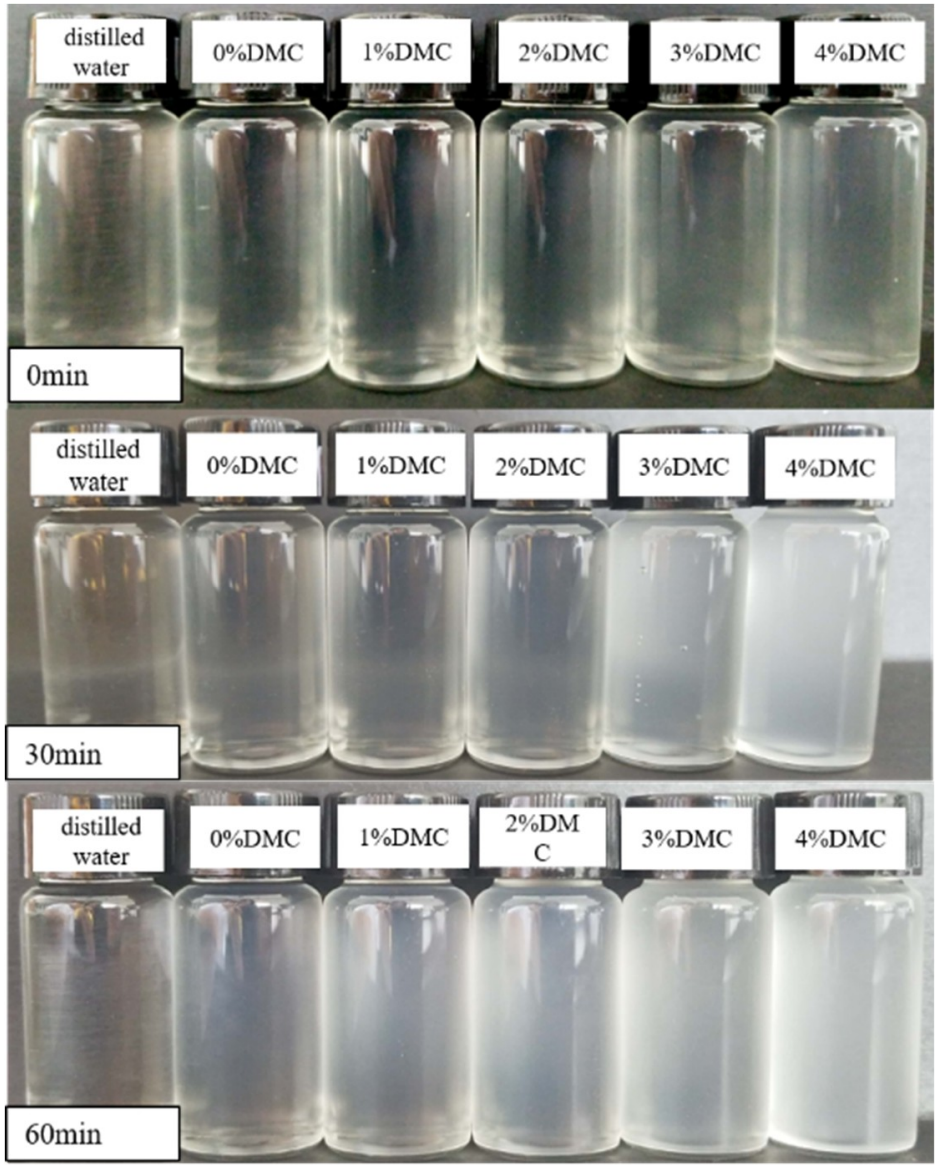

Figure 3. Photography of different concentrations of the solution under different ultrasound.

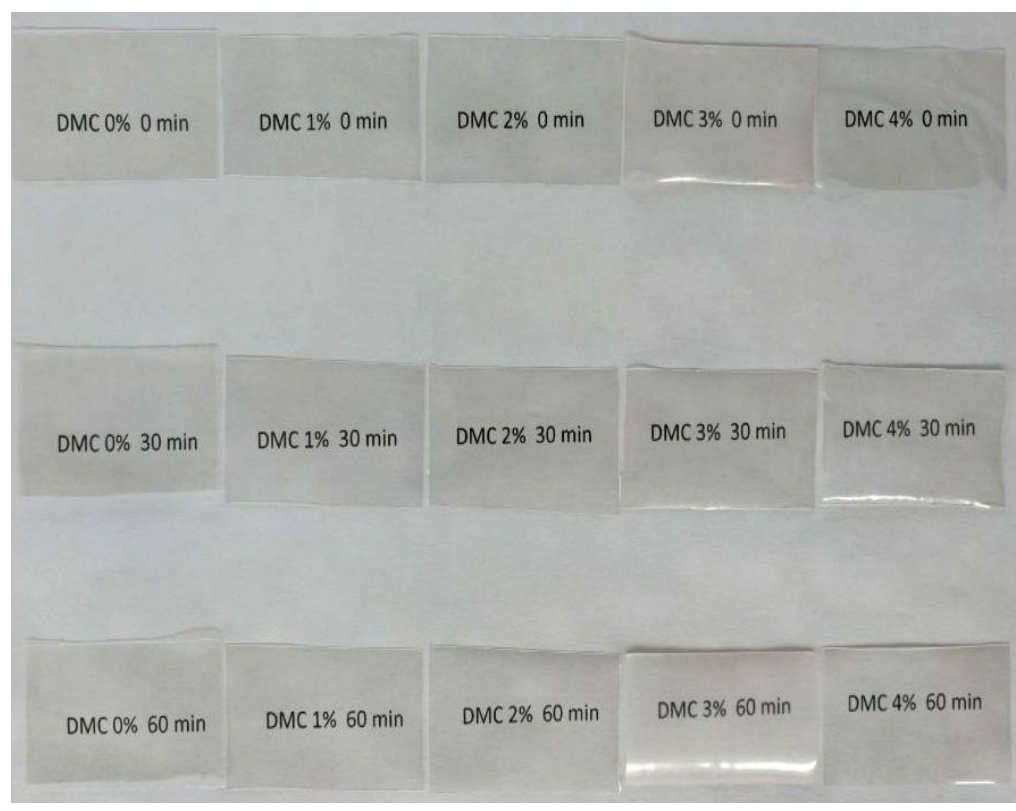

Figure 4. Photography of different composite films under different ultrasound.

As shown in Figure 5, Water vapor loss can be reduced by ultrasound for $30 \mathrm{~min}$, which is better than $1 \mathrm{~h}$ by ultrasound. It has been testified that the turbulent effect exerted by ultrasonic cavitation leads to collision and high-speed oscillations of the particles, thus accelerating the interaction between composites and making them disperse more uniformly [42]. Owning to fixed vibration exhibiting 
high frequency, all substances of polymers could be vibrated with high kinetic energy to be able to move. The kinetic power leads to the probability of DMC to separate separately as well as distribute homogeneously in the matrix consequently. It facilitates the interaction between DMC and PVA/CS and makes the structure of composite films more compact, thus reducing the WVP of composite films. Density measurements can also illustrate this point. However, when the ultrasonic time was too long (60 min), which may cause the excessive damage to the polymer, excessive pores on the polymer surface resulted, thus increasing its WVP [42].

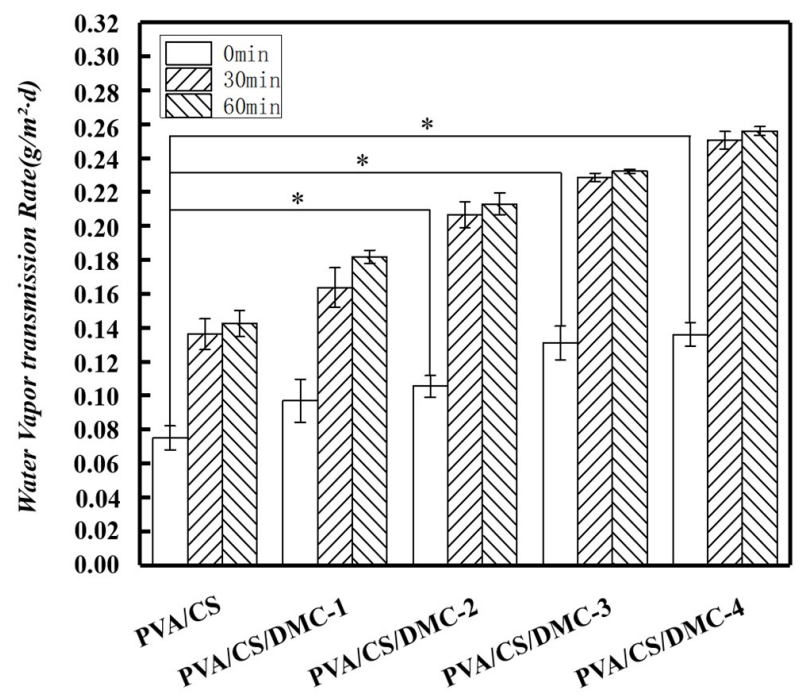

Figure 5. Water vapor rate of different composite films under different ultrasound times. a Values marking various superscripts for every parameter within the same ultrasound times differ noticeably $(p<0.05)$.

\subsection{The Light Transmittance of PVA/CS/DMC Composite Films}

As demonstrated in Figure 6, the PVA/CS films illustrated an increase in light transmittance after DMC addition. The rising concentration of DMC could enhance the light transmittance of PVA/CS compound films. Under the concentrations of DMC at $1 \%$, the light maximum transmittance is $89.65 \% \pm 0.32 \%, 7.60 \%$ higher than that of PVA/CS composite films $(p<0.05)$.

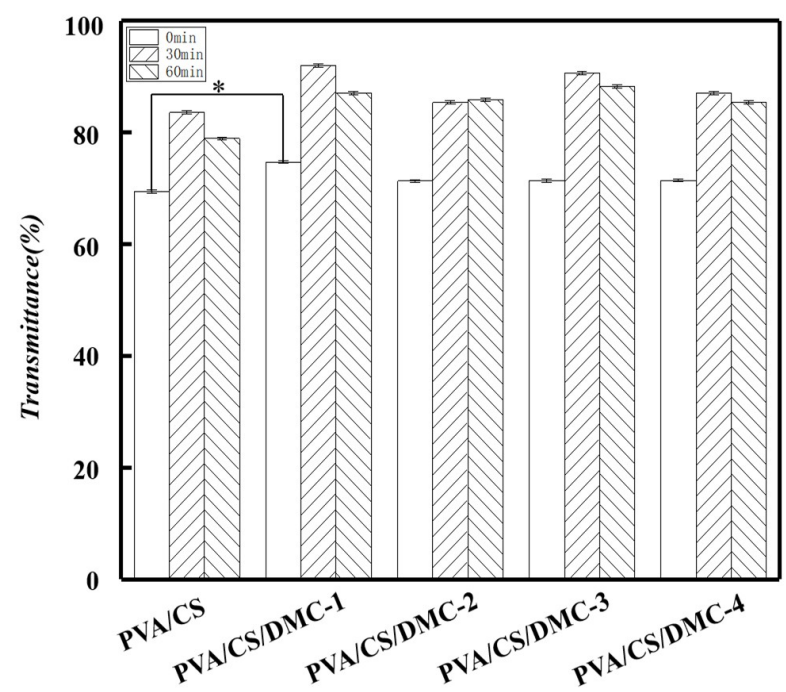

Figure 6. Transmittance of different composite films in the case of varying ultrasonication time. a Values marking various superscripts for every parameter within the same ultrasound times differ noticeably $(p<0.05)$. 
PVA/CS/DMC composite films' light transmittance could be enhanced through ultrasonication. With the extension of ultrasonication duration, an increasing trend was illustrated by light transmittance of PVA/CS/DMC composite films generally, and then by a decrease. The light transmittance that was reached for the highest value was lighted by him when the films were processed for $30 \mathrm{~min}$. In brief, after $30 \mathrm{~min}$ of ultrasonication, $15.2 \% \pm 2.95 \%$ by the light transmittance of the composite PVA/CS/DMC film with DMC at the concentration of $2 \%$ was reached. These consequences may be due to the super-mixing impact of ultrasonication, which may have led to the more uniform DMC molecules distribution in the composite films and lowered the presence of the bubbles in the solution.

\subsection{The Measurement of Color Properties and Opacity of PVA/CS/DMC Composite Films}

The color and opaqueness of the bioactive eatable films, as a packaging material, are essential factors concerning consumer acceptance. The effects of the type of DMC concentration on the optical properties of the composite films are indicated in Table 2. The opacity consequences and color implied that the PVA/CS/DMC films were colorless and pellucid. These PVA/CS/DMC films could then be used as packaging for products demanding high transparency as it allows the consumer to observe the product through colorless material. According to our findings, The $L^{*}$ values were between 87.37 and 88.17 (Table 2) suggesting that the PVA/CS, PVA/CS/DMC-1, PVA/CS/DMC-2, and PVA/CS/DMC-3 show a slight tendency towards lucency. The $a^{*}$ (green-red) values between -0.15 and 1.26 (Table 2) reveals that the PVA/CS, PVA/CS/DMC-1, PVA/CS/DMC-2, and PVA/CS/DMC-3 show a slight tendency towards redness and the PVA/CS/DMC-4 films to greenness. The $b^{*}$ (yellow-blue) values were between -5.51 and -3.29 (Table 2), implying that the PVA/CS, PVA/CS/DMC-1, PVA/CS/DMC-2, and PVA/CS/DMC-3 show a slight tendency towards blueness. Ultrasonication has a certain effect on film color. Under the ultrasonic time of $30 \mathrm{~min}$, the $L^{*}$-value and $b^{*}$-value of the PVA/CS/DMC films increased slightly $(p>0.05)$, while the $a^{*}$-value decreased slightly $(p<0.05)$. However, when the ultrasonic time was prolonged to $60 \mathrm{~min}$, the ultrasonication led the $L^{*}$-value, $b^{*}$-value, and $a^{*}$-value decreased slightly $(p<0.05)$.

Table 2. Color properties of different composite films in the case of varying ultrasonication time.

\begin{tabular}{ccccc}
\hline Film & $\boldsymbol{L}^{*}$ & $\boldsymbol{a}^{*}$ & $\boldsymbol{b}^{*}$ & $\Delta \boldsymbol{E}^{*}$ \\
\hline PVA/CS-0 & $88.17 \pm 0.65^{\mathrm{Aa}}$ & $1.26 \pm 0.21^{\mathrm{Aa}}$ & $-5.51 \pm 0.4^{\mathrm{Bb}}$ & $1.40 \pm 0.39^{\mathrm{Ac}}$ \\
PVA/CS-30 & $88.45 \pm 0.11^{\mathrm{Aa}}$ & $0.73 \pm 0.08^{\mathrm{Ba}}$ & $-4.79 \pm 0.11^{\mathrm{Aa}}$ & $1.82 \pm 0.11^{\mathrm{Ab}}$ \\
PVA/CS-60 & $88.38 \pm 0.19^{\mathrm{Aa}}$ & $0.72 \pm 0.15^{\mathrm{Ba}}$ & $-4.61 \pm 0.15^{\mathrm{Ac}}$ & $1.96 \pm 0.25^{\mathrm{Ac}}$ \\
PVA/CS/DMC-1-0 & $88.30 \pm 0.09^{\mathrm{Aa}}$ & $0.73 \pm 0.15^{\mathrm{Aab}}$ & $-4.47 \pm 0.05^{\mathrm{Aa}}$ & $0.82 \pm 0.09^{\mathrm{Ad}}$ \\
PVA/CS/DMC-1-30 & $87.86 \pm 0.28^{\mathrm{Aa}}$ & $0.40 \pm 0.14^{\mathrm{Aab}}$ & $-4.36 \pm 0.19^{\mathrm{Abc}}$ & $0.41 \pm 0.24^{\mathrm{Ac}}$ \\
PVA/CS/DMC-1-60 & $88.01 \pm 0.27^{\mathrm{Aab}}$ & $0.48 \pm 0.20^{\mathrm{Aab}}$ & $-4.39 \pm 0.28^{\mathrm{Ac}}$ & $0.61 \pm 0.20^{\mathrm{Ad}}$ \\
PVA/CS/DMC-2-0 & $88.48 \pm 0.17^{\mathrm{Aa}}$ & $0.64 \pm 0.16^{\mathrm{Aab}}$ & $-4.42 \pm 0.18^{\mathrm{Aa}}$ & $2.12 \pm 0.27^{\mathrm{Ab}}$ \\
PVA/CS/DMC-2-30 & $88.42 \pm 0.15^{\mathrm{Aa}}$ & $0.39 \pm 0.18^{\mathrm{Aab}}$ & $-4.16 \pm 0.20^{\mathrm{Aab}}$ & $2.48 \pm 0.27^{\mathrm{Aab}}$ \\
PVA/CS/DMC-2-60 & $88.16 \pm 0.55^{\mathrm{Aa}}$ & $0.23 \pm 0.34^{\mathrm{Aabc}}$ & $-3.94 \pm 0.31^{\mathrm{Ab}}$ & $2.83 \pm 0.63^{\mathrm{Ab}}$ \\
PVA/CS/DMC-3-0 & $88.14 \pm 0.18^{\mathrm{Aa}}$ & $0.23 \pm 0.39^{\mathrm{Ab}}$ & $-4.32 \pm 0.13^{\mathrm{Ba}}$ & $0.72 \pm 0.22^{\mathrm{Ad}}$ \\
PVA/CS/DMC-3-30 & $87.78 \pm 0.28^{\mathrm{Aa}}$ & $0.19 \pm 0.19^{\mathrm{Aab}}$ & $-3.93 \pm 0.12^{\mathrm{ABa}}$ & $0.57 \pm 0.16^{\mathrm{Ac}}$ \\
PVA/CS/DMC-3-60 & $87.92 \pm 0.26^{\mathrm{Aab}}$ & $0.04 \pm 0.12^{\mathrm{Abc}}$ & $-3.76 \pm 0.13^{\mathrm{Ab}}$ & $0.79 \pm 0.05^{\mathrm{Ad}}$ \\
PVA/CS/DMC-4-0 & $88.46 \pm 0.21^{\mathrm{Aa}}$ & $0.17 \pm 0.15^{\mathrm{Aab}}$ & $-4.01 \pm 0.17^{\mathrm{Ba}}$ & $2.72 \pm 0.26^{\mathrm{Aa}}$ \\
PVA/CS/DMC-4-30 & $87.71 \pm 0.33^{\mathrm{ABa}}$ & $-0.11 \pm 0.28^{\mathrm{Ab}}$ & $-3.78 \pm 0.30^{\mathrm{ABc}}$ & $3.27 \pm 0.49^{\mathrm{Aa}}$ \\
PVA/CS/DMC-4-60 & $87.37 \pm 0.27^{\mathrm{Bb}}$ & $-0.15 \pm 0.18^{\mathrm{Ac}}$ & $-3.29 \pm 0.31^{\mathrm{Aa}}$ & $3.81 \pm 0.35^{\mathrm{Aa}}$ \\
\hline
\end{tabular}

$a$ Values marking various superscripts for every parameter within the same concentrations are significantly different $(p<0.05)$; $A$ Values marking various superscripts for every parameter within the same ultrasound times differ noticeably $(p<0.05)$.

\subsection{Mechanical Properties of PVA/CS/DMC Composite Films}

A signification of the strength and elasticity of composite films is provided by tensile testing [39]. The PVA/CS fiber without DMC exhibited an elongation at break of $240.57 \% \pm 5.70 \%$ and tensile strength of $20.83 \mathrm{MPa} \pm 1.54 \mathrm{MPa}$ (Table 3). At the identical ultrasonic time, when the DMC concentration 
grew from $1 \%$ to $4 \%$, the tensile strength of the fiber grew first then declined on the whole, while the elongation at break generally grew first then declined. [26]. When DMC concentrations of the composite film were at $2 \%$, the elongation at break was the highest at $273.70 \% \pm 4.86 \%$ (without sonication), $13.83 \%$ better than PVA/CS film $240.44 \% \pm 6.19 \%$. With the rise in the dosage of DMC, DMC that is inclined to aggregate to decrease the surface free power, caused a decline in the hydrogen that bonded between DMC and the polymers. Accordingly, the general strength of composite films was declined [43]. In the present research, when the DMC content got to $8 \mathrm{~g}$, the tensile strength falls intensely to $3.19 \mathrm{MPa} \pm 0.62 \mathrm{MPa}$ since this high concentration of DMC could not be assimilated homogeneously into the film matrix [44]. The film thickness was slightly affected by DMC addition, presumably because the additives were able to be widely distributed in CS matrix.

Strain and tensile strength are shown in Table 3 at the break of the films that are produced from the non-sonicated and sonicated composite films. Over time, the tensile strength values for all sonicated composite film $(0 \% \sim 2 \% \mathrm{DMC})$ were higher than that for the non-sonicated ones owning to the enhanced interfacial hydrogen that bonded between it and matrix. However, as with increasing the time of the ultrasound, the sonicated composite films' tensile strength $(3 \% \sim 4 \% \mathrm{DMC})$ was lower than that for the non-sonicated ones. When the ultrasonic time was $30 \mathrm{~min}$, the elongation at the break of the films increased significantly $(p<0.05)$, whereas its tensile strength generally displayed a decreasing trend. However, when the ultrasonic time was extended to $60 \mathrm{~min}$, the overall mechanical properties of the film were decreased by ultrasonication.

Table 3. Mechanical strength and density properties of different composite films in the case of varying ultrasonication time.

\begin{tabular}{ccccc}
\hline Samples & Stress (MPa) & Strain $\mathbf{( \% )}$ & Thickness $(\mathbf{m m})$ & Density $\left.\mathbf{( g / \mathbf { c m } ^ { 3 }}\right)$ \\
\hline PVA/CS-0 & $21.91 \pm 0.34^{\mathrm{Aa}}$ & $240.44 \pm 6.19^{\mathrm{Bb}}$ & $0.05 \pm 0.01^{\mathrm{Aa}}$ & $1.24 \pm 0.02^{\mathrm{Ab}}$ \\
PVA/CS-30 & $22.07 \pm 0.35^{\mathrm{Aa}}$ & $281.76 \pm 0.30^{\mathrm{Ba}}$ & $0.10 \pm 0.02^{\mathrm{Aa}}$ & $1.39 \pm 0.01^{\mathrm{Aa}}$ \\
PVA/CS-60 & $22.01 \pm 0.18^{\mathrm{Aa}}$ & $256.83 \pm 9.49^{\mathrm{Ab}}$ & $0.07 \pm 0.01^{\mathrm{Ca}}$ & $1.28 \pm 0.02^{\mathrm{ABb}}$ \\
PVA/CS/DMC-1-0 & $13.28 \pm 0.11^{\mathrm{Ba}}$ & $75.27 \pm 2.97^{\mathrm{Ca}}$ & $0.11 \pm 0.01^{\mathrm{Ab}}$ & $1.24 \pm 0.01^{\mathrm{Ab}}$ \\
PVA/CS/DMC-1-30 & $16.34 \pm 2.67^{\mathrm{Ca}}$ & $60.23 \pm 6.54^{\mathrm{Ca}}$ & $0.14 \pm 0.02^{\mathrm{Aa}}$ & $1.35 \pm 0.02^{\mathrm{Aa}}$ \\
PVA/CS/DMC-1-60 & $13.56 \pm 0.59^{\mathrm{ABa}}$ & $78.93 \pm 7.39^{\mathrm{Ba}}$ & $0.11 \pm 0.01^{\mathrm{ABab}}$ & $1.26 \pm 0.02^{\mathrm{ABb}}$ \\
PVA/CS/DMC-2-0 & $11.65 \pm 0.21^{\mathrm{Ca}}$ & $273.70 \pm 4.86^{\mathrm{Ab}}$ & $0.10 \pm 0.02^{\mathrm{Aa}}$ & $1.31 \pm 0.03^{\mathrm{Ab}}$ \\
PVA/CS/DMC-2-30 & $17.35 \pm 2.72^{\mathrm{Ba}}$ & $347.06 \pm 21.31^{\mathrm{Aa}}$ & $0.10 \pm 0.02^{\mathrm{Aa}}$ & $1.40 \pm 0.02^{\mathrm{Aa}}$ \\
PVA/CS/DMC-2-60 & $15.00 \pm 0.65^{\mathrm{Aa}}$ & $277.85 \pm 15.14^{\mathrm{Ab}}$ & $0.08 \pm 0.02^{\mathrm{BCa}}$ & $1.31 \pm 0.02^{\mathrm{Ab}}$ \\
PVA/CS/DMC-3-0 & $10.46 \pm 0.06^{\mathrm{Da}}$ & $44.24 \pm 0.05^{\mathrm{Db}}$ & $0.12 \pm 0.02^{\mathrm{Aa}}$ & $1.23 \pm 0.02^{\mathrm{Ab}}$ \\
PVA/CS/DMC-3-30 & $10.70 \pm 0.01^{\mathrm{Da}}$ & $44.14 \pm 0.05^{\mathrm{Cb}}$ & $0.10 \pm 0.02^{\mathrm{Aa}}$ & $1.35 \pm 0.02^{\mathrm{Aa}}$ \\
PVA/CS/DMC-3-60 & $10.49 \pm 0.26^{\mathrm{Ba}}$ & $83.43 \pm 7.07^{\mathrm{Ba}}$ & $0.13 \pm 0.02^{\mathrm{Aa}}$ & $1.27 \pm 0.01^{\mathrm{ABb}}$ \\
PVA/CS/DMC-4-0 & $3.19 \pm 0.62^{\mathrm{Ea}}$ & $55.40 \pm 2.29^{\mathrm{Da}}$ & $0.11 \pm 0.02^{\mathrm{Ab}}$ & $1.22 \pm 0.04^{\mathrm{Aa}}$ \\
PVA/CS/DMC-4-30 & $4.63 \pm 0.18^{\mathrm{Ea}}$ & $62.44 \pm 1.00^{\mathrm{Ca}}$ & $0.08 \pm 0.02^{\mathrm{Aa}}$ & $1.24 \pm 0.02^{\mathrm{Ba}}$ \\
PVA/CS/DMC-4-60 & $3.81 \pm 0.62^{\mathrm{Ca}}$ & $67.83 \pm 10.54^{\mathrm{Ba}}$ & $0.08 \pm 0.02^{\mathrm{BCb}}$ & $1.22 \pm 0.02^{\mathrm{Aba}}$ \\
\hline
\end{tabular}

Values marking various lowercase superscripts for every parameter within the same concentrations differ noticeably $(p<0.05)$; Values marking various uppercase superscripts for every parameter within the same ultrasound times differ noticeably $(p<0.05)$.

\subsection{Density Test of PVA/CS/DMC Composite Films}

PVA/CS densities are indicated in Table 3 and other PVA/CS/DMC composite films in the case of varying ultrasonication time [7]. In comparison with the PVA/CS composite film, different concentrations of DMC slightly impacted the density of the composite film. By increasing the DMC concentration, we observed an increment in the density of composite films at initial times, whereas it declined at later stages. The concentration of DMC at $2 \%$ was found as the maximum $1.33 \mathrm{~g} / \mathrm{cm}^{3} \pm$ $0.07 \mathrm{~g} / \mathrm{cm}^{3}$.

Present findings revealed that the density of the PVA/CS, PVA/CS/DMC-1, PVA/CS/DMC-2, and PVA/CS/DMC-3 composite films increased significantly at the ultrasonic time of $30 \mathrm{~min} .(p<0.05)$, but when the ultrasonic time was extended to $60 \mathrm{~min}$, the density of the PVA/CS/DMC composite film was 
not significantly increased compared with the PVA/CS film $(p>0.05)$. This is presumably attributed to the cavitation effect of ultrasonication [45]. When the ultrasound time was short (30 $\mathrm{min})$, appropriate ultrasonic time can make ultrasound through a liquid creating pressure for the formation of a network structure with increased density and uniformity. However, excessive duration of ultrasonic time (60 $\mathrm{min}$ ) may cause excessive damage to the polymer, resulting in excessive pores on the polymer surface to reduce its density [42].

\subsection{Moisture Contents of PVA/CS/DMC Composite Films}

Figure 7 shows that when the content of DMC was up-regulated from $0 \%$ to $4 \%$ on chitosan basis, PVA/CS/DMC films' moisture contents were significantly up-regulated from $19.86 \%$ to $27.67 \%$ $(p<0.05)$. PVA/ CS film showed higher moisture content, attributed to ample hydrophilic groups in chitosan molecules, particularly $-\mathrm{OH}$ and $-\mathrm{NH}_{2}$. After adding DMC to chitosan film, intra-PVA and inter-PVA hydrogen bonds were weakened. As a result, interactions between moisture and chitosan were weakened. Higher moisture contents thus were presented by PVA/CS/DMC films in comparison to PVA/CS film [46]. The hydrogen bond between PVA and DMC molecules was influenced by ultrasonication. This is presumably because of ultrasonic cavitation, which probably damaged the hydrogen bonds that were constituted between DMC and PVA, thereby releasing the intermolecular hydroxyl groups. For this reason, the sonicated composite films were higher than that for the non-sonicated ones.

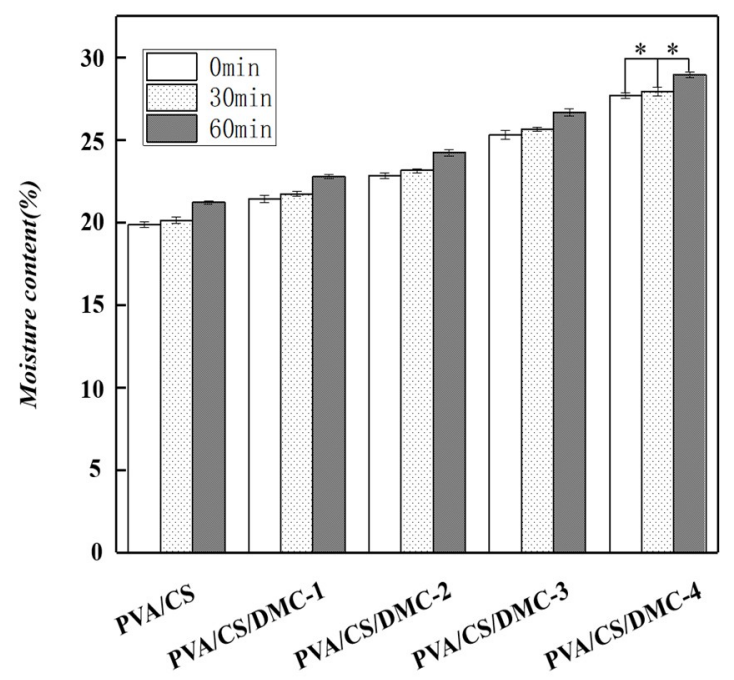

Figure 7. Moisture contents of different composite films in the case of varying ultrasonication time.

* Values marking various superscripts for every parameter within the same ultrasound times differ noticeably $(p<0.05)$.

\subsection{Degradation Percentages of PVA/CS/DMC Composite Films}

Figure 8 shows the biodegradable films covered by soil for 30 days, showing $60 \%$ degradation percentage of PVA/CS/DMC. PVA/CS/DMC biodegradable films can break down rapidly in comparison with the food packages circulating on the market at the present time. That is to say, when PVA/CS/DMC biodegradable films are removed, their degradation is instant owing to the dissolution as compared to other food packaging materials available on the market that are not easily degradable and cause environmental pollution.

As shown in Figure 8, the degradation percentage of DMC composite membrane with $2 \%$ concentration increased with the extension of ultrasonication time, while the degradation rate without ultrasonication was observed $66.22 \% \pm 0.26 \%$ only. This is in contrast with the degradation of $76.17 \% \pm 1.51 \%$ after being treated ultrasonically for 30 min merely, suggesting that the addition of DMC raised the degradation percentages of the PVA/CS/DMC film. The likely reason for this 
is that DMCs are a class of natural, degradable biomaterials, and when they are being degraded, the intermolecular polymer chains of PVA may be destroyed, which accelerates and promotes PVA degradation. According to the consequences discussed above, the composite film with the DMC concentration of $2 \%$ was assessed as having the most effective degradation. The degradation percentage of the composite film may have been improved by ultrasonication owning to the cavitation and super-mixing effects, which conferred a smoother surface, making the film more liable to degradation. The biodegradability of a blend of PVA and collagen hydrolysates was explored by Alexy et al. [47] as well. They reported that collagen hydrolysates addition makes PVA membrane more biodegradable.

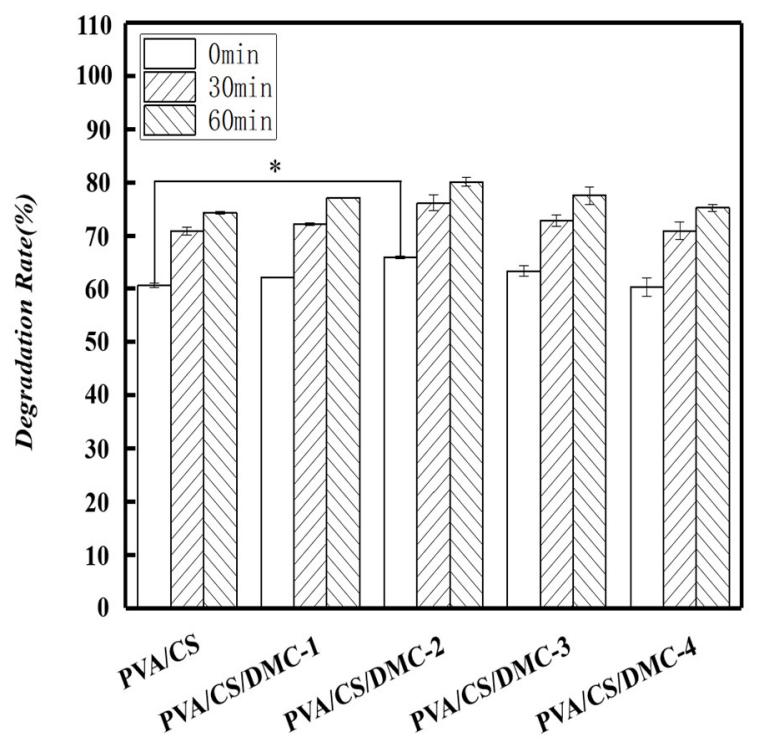

Figure 8. Degradation rate of different composite films in the case of varying ultrasonication time. a Values marking various superscripts for every parameter within the same ultrasound times differ noticeably $(p<0.05)$.

\subsection{Antibacterial Properties of PVA/CS/DMC Composite Films}

Table 4 shows the PVA/CS/DMC-2 films' antibacterial efficiency with various DMC concentrations. Existing studies have shown that PVA/CS film is antimicrobial against E. coli [9] and S. aureus [48]. Numerous studies have found that the increase of free amino group of CS in the composite membrane is its antibacterial mechanism. The amino group charged positively interacts with the negatively charged bacterial membrane, which causes the leakage of protein components within the microbial cell [49]. In this study, the PVA/CS/DMC film was significantly more antimicrobial than PVA/CS film $(p<0.05)$, presumably attributed to the more antibacterial activity of DMC. Quaternary ammonium chemical compounds can be used as bactericides by charge attractiveness, infiltration, and diffusion [50]. It is recognized that the reported antibacterial activities of chitosan $(\mathrm{pKa} \approx 6.3)$ were restricted to acidic conditions for its low solubility below neutral $\mathrm{pH}$, and solubility has been improved by quaternary ammonium chitosan derivatives normally, antibacterial activity.

Table 4. Antimicrobial effect of the typical PVA/CS/DMC composite films with a concentration of $2 \%$ under different ultrasound times against Escherichia coli, Staphylococcus aureus.

\begin{tabular}{ccc}
\hline Sample & S. aureus & E. coli \\
\hline PVA/CS & $52.88 \pm 2.50^{\mathrm{c}}$ & $45.19 \pm 2.12^{\mathrm{c}}$ \\
PVA/CS/DMC-2\%-0 min & $62.12 \pm 1.35^{\mathrm{b}}$ & $54.04 \pm 0.67^{\mathrm{b}}$ \\
PVA/CS/DMC-2\%-30 min & $79.23 \pm 1.92^{\mathrm{a}}$ & $72.31 \pm 1.35^{\mathrm{a}}$ \\
PVA/CS/DMC-2\%-60 min & $81.15 \pm 0.38^{\mathrm{a}}$ & $74.42 \pm 1.06^{\mathrm{a}}$
\end{tabular}

$a$ Values marking various superscripts for every parameter within the same concentrations are significantly different $(p<0.05)$. 
Ultrasonication can, to a certain extent, up-regulate materials' bacteriostatic effects. In this study, the PVA/CS/DMC-2 film(ultrasound) was significantly more antimicrobial than PVA/CS/DMC-2 film (without ultrasound) $(p<0.05)$. In comparison with ultrasonic $30 \mathrm{~min}$, the results here indicated S. aureus and E. coli growth inhibition was insignificantly up-regulated to $81.15 \% \pm 0.38 \%$ and $74.42 \% \pm 1.06 \%$ after $60 \mathrm{~min}$ ultrasonication, respectively. It has been reported that tannin polyurethane prepared from black wattle bark tannin has a certain inhibiting effect on S. aureus, Proteus vulgaris (P. vulgaris), E. coli, and some other bacteria [51] Thus, the beneficial affect of ultrasonication on the antibacterial characteristics of films is worthy of subsequent research.

\section{Conclusion}

In the present study, PVA/CS/DMC packaging substances with bacteriostatic activity were successfully prepared by using the polymer blended approach. We researched the effects of ultrasonication period on composite films' characteristics. The consequences showed that though ultrasonication split the elongation and tensile strength down at the break for these ingredients in its early phases, it could enhance their barrier property and light transmittance performance. On the whole, the results revealed that the tensile strength and elongation at the break of the composite films were up-regulated by the ultrasonication. The optimal PVA/CS/DMC-2 composite film exhibited notable activity against $E$. coli and $S$. aureus. Though the mechanism leading to the improvement in ultrasonic processing-induced bacteriostatic activity of PVA/CS/DMC composite films require further study. This composite film type's biodegradability characteristics and high physical characteristics verified its applicability as an antibacterial and biodegradable active material for packaging.

Author Contributions: R.L. wrote the manuscript, Y.W. developed the protocol, J.X. prepared the manuscript, S.A. contributed to review and edit the manuscript, Y.L. is the guarantor.

Funding: This work was supported by Sichuan Science and Technology Program (2018RZ0034), China Scholarship Council Project (201806915013), and Natural Science Fund of Education Department of Sichuan Province (16ZB0044 and 035Z1373).

Conflicts of Interest: The authors declare no conflict of interest.

\section{References}

1. Azeredo, D.; Henriette, M.C. Nanocomposites for food packaging applications. Food Res. Int. 2009, 42, 1240-1253. [CrossRef]

2. Dutta, P.K.; Tripathi, S.; Mehrotra, G.K.; Dutta, J. Perspectives for chitosan-based antimicrobial films in food applications. Food Chem. 2009, 114, 1173-1182. [CrossRef]

3. Nur Hanania, Z.A.; Roos, Y.H.; Kerry, J.P. Use and application of gelatin as potential biodegradable packaging materials for food products. Int. J. Biol. Macromol. 2014, 71, 94-102. [CrossRef]

4. Li, X.X.; Shi, X.W.; Wang, M.; Du, Y.M. Xylan chitosan conjugate-A potential food preservative. Food Chem. 2011, 126, 520-525. [CrossRef]

5. Mendes, F.R.S.; Bastos, M.S.R.; Mendes, L.G.A.; Silva, R.A.; Sousa, F.D.; MonteiroMoreira, A.C.O.; Cheng, H.N.; Biswas, A.; Moreira, R.A. Preparation and evaluation of hemicellulose films and their blends. Food Hydrocolloid. 2017, 70, 181-190. [CrossRef]

6. Yu, Z.; Li, B.Q.; Chu, J.; Zhang, P. Silica in situ enhanced PVA/chitosan biodegradable films for food packages. Carbohydr. Polym. 2017, 184, 214. [CrossRef]

7. Ye, J.S.; Wang, S.Y.; Lan, W.J.; Qin, W.; Liu, Y.W. Preparation and properties of polylactic acid-tea polyphenol-chitosan composite membranes. Int. J. Biol. Macromol. 2018, 117, 632-639. [CrossRef]

8. Tripathi, S.; Mehrotra, G.K.; Dutta, P.K. Physicochemical and bioactivity of cross-linked chitosan-PVA film for food packaging applications. Int. J. Biol. Macromol. 2009, 45, 372-376. [CrossRef]

9. Hu, D.Y.; Wang, L.J. Fabrication of antibacterial blend film from poly (vinyl alcohol) and quaternized chitosan for packaging. Mater. Res. Bull. 2016, 78, 46-52. [CrossRef] 
10. Jridi, M.; Hajji, S.; Ayed, H.B.; Lassoued, I.; Mbarek, A.; Kammoun, M.; Souissi, N.; Nasri, M. Physical, structural, antioxidant and antimicrobial properties of gelatin-chitosan composite edible films. Int. J. Biol. Macromol. 2014, 67, 373-379. [CrossRef]

11. Liu, Y.W.; Wang, S.Y.; Zhang, R. Composite poly(lactic acid)/chitosan nanofibrous scaffolds for cardiac tissue engineering. Int. J. Biol. Macromol. 2017, 103, 373-379. [CrossRef]

12. Wang, H.L.; Zhang, R.; Zhang, H.; Jiang, S.W.; Liu, H.; Sun, M.; Jiang, S.T. Kinetics and functional effectiveness of nisin loaded antimicrobial packaging film based on chitosan/poly(vinyl alcohol). Carbohydr. Polym. 2015, 127, 64-71. [CrossRef]

13. Cazón, P.; Velazquez, G.; Ramírez, J.A.; Vázquez, M. Polysaccharide-based films and coatings for food packaging: A review. Food Hydrocolloid. 2017, 68, 136-148. [CrossRef]

14. Liu, Y.W.; Wang, S.Y.; Lan, W.T. Fabrication of antibacterial chitosan-PVA blended film using electrospray technique for food packaging applications. Int. J. Biol. Macromol. 2017, 107, 8448-8854. [CrossRef]

15. Wang, J.H.; Wang, L.; Yu, H.J.; Abdin, Z.; Chen, Y.; Chen, Q.; Zhou, W.D.; Zhang, H.T.; Chen, X. Recent progress on synthesis, property and application of modified chitosan: An overview. Int. J. Biol. Macromol. 2016, 88, 333-344. [CrossRef]

16. Sin, L.T.; Rahman, W.A.W.A.; Rahmat, A.R.; Khan, M.I. Detection of synergistic interactions of polyvinyl alcohol-cassava starch blends through DSC. Carbohydr. Polym. 2010, 79, 224-226. [CrossRef]

17. Dai, H.G.; Chang, P.R.; Yu, J.G.; Ma, X.F.; Zhou, P. Preparation and properties of thermoplastic pea starch using N,N-bis(2-hydroxyethyl)formamide as the plasticizer. Polym. Eng. Sci. 2010, 50, 970-977. [CrossRef]

18. Ye, Q.; Zhang, Z.C.; Ge, X.W. Highly efficient flocculant synthesized through the dispersion copolymerization of water-soluble monomers induced by $\gamma$-ray irradiation: Synthesis and polymerization kinetics. J. Appl. Polym. Sci. 2003, 89, 8. [CrossRef]

19. Abdollahi, Z.; Frounchi, M.; Dadbin, S. Synthesis, characterization and comparison of PAM, cationic pdmc and p(am-co-dmc) based on solution polymerization. J. Ind. Eng. Chem. 2011, 17, 580-586. [CrossRef]

20. Ochoa, J.R.; Sanz, F.J.E.; Sasia, P.M.; Santos García, A.; Díaz de Apodaca, E.; Río, P. Synthesis of cationic flocculants by the inverse microemulsion copolymerization of acrylamide with $60 \% 2$-acryloxyethyltrimethyl ammonium chloride in the monomer feed. ii. influence of the formulation composition, hydrophilic-lipophilic balance, starting polymerization temperature, and reaction time. J. Clin. Pathol. 2007, 103, 186-197. [CrossRef]

21. Agha, H.; Pedram, F. Cationic kraft lignin-acrylamide copolymer as a flocculant for clay suspensions: (2) Charge density effect. Sep. Purif. Technol. 2019, 210, 963-972. [CrossRef]

22. Wang, B.; Zhang, Y.; Miao, C. Preparation of cationic chitosan-polyacrylamide flocculant and its properties in wastewater treatment. J. Ocean. U. China. 2011, 10, 42-46. [CrossRef]

23. Wang, L.J.; Wang, J.P.; Zhang, S.J.; Chen, Y.Z.; Yuan, S.J.; Sheng, G.P.; Yu, H.Q. A water-soluble cationic flocculant synthesized by dispersion polymerization in aqueous salts solution. Sep. Purif. Technol. 2009, 67, 331-335. [CrossRef]

24. Chen, J.H.; Liu, Q.L.; Fang, J.; Zhu, A.M.; Zhang, Q.G. Composite hybrid membrane of chitosan-silica in pervaporation separation of MEOH/DMC mixtures. J. Colloid Interface Sci. 2007, 316, 580-588. [CrossRef]

25. Liu, Y.W.; Wang, S.Y.; Lan, W.J.; Qin, W. Development of ultrasound treated polyvinyl alcohol/tea polyphenol composite films and their physicochemical properties. Ultrason. Sonochem. 2019, 51, 386-394. [CrossRef]

26. ASTM E96-00. Standard test methods for water vapour transmission of materials; ASTM International: West Conshohocken, PA, USA, 2000. [CrossRef]

27. Zhang, D.; Zhou, W.; Wei, B.; Wang, X.; Tang, R.P.; Nie, J.M.; Wang, J. Carboxyl-modified poly(vinyl alcohol)-crosslinked chitosan hydrogel films for potential wound dressing. Carbohydr. Polym. 2015, 125, 189-199. [CrossRef]

28. Yu, Z.L.; Alsammarraie, F.K.; Nayigiziki, F.X.; Wang, W.; Vardhanabhuti, B.; Mustapha, A.; Lin, M. Effect and mechanism of cellulose nanofibrils on the active functions of biopolymer-based nanocomposite films. Food Res. Int. 2017, 99, 166-172. [CrossRef]

29. Vaezi, K.; Asadpour, G.; Sharifi, H. Effect of ZnO nanoparticles on the mechanical, barrier and optical properties of thermoplastic cationic starch/montmorillonite biodegradable films. Int. J. Biol. Macromol. 2019, 124, 519-529. [CrossRef]

30. Peng, Y.; Wu, Y.; Li, Y.F. Development of tea extracts and chitosan composite films for active packaging materials. Int. J. Biol. Macromol. 2013, 59, 282-289. [CrossRef] 
31. Sun, L.J.; Sun, J.J.; Chen, L.; Niu, P.F.; Yang, X.B.; Guo, Y.R. Preparation and characterization of chitosan film incorporated with thinned young apple polyphenols as an active packaging material. Carbohydr. Polym. 2017, 163, 81-91. [CrossRef]

32. Kim, E.Y.; Yoo, Y.T.; Im, S.S. Effect of hydrophilicity on the biodegradability of polyesteramides. J. Appl. Poly. Sci. 2003, 90, 2708-2714. [CrossRef]

33. García, M.A.; Pinottia, A.; Martino, M.N.; Zaritzky, N.E. Characterization of composite hydrocolloid films. Carbohydr. Polym. 2004, 56, 339-345. [CrossRef]

34. Rivero, S.; García, M.A.; Pinotti, A. Crosslinking capacity of tannic acid in plasticized chitosan films. Carbohydr. Polym. 2011, 82, 270-276. [CrossRef]

35. Sánchez-González, L.; Saavedra, J.I.Q.; Chiralt, A. Antilisterial and physical properties of biopolymer films containing lactic acid bacteria. Food Control. 2014, 35, 200-206. [CrossRef]

36. Krishna Rao, K.S.V.; Subha, M.C.S.; Sairam, M.; Mallikarjuna, N.N.; Aminabhavi, T.M. Blend membranes of chitosan and poly(vinyl alcohol) in pervaporation dehydration of isopropanol and tetrahydrofuran. J. Appl. Polym. Sci. 2007, 103, 1918-1926. [CrossRef]

37. Chenaria, H.M.; Kangarlou, H. Electrospun tungsten oxide NPs/PVA nanofibers: A study on the morphology and Kramers-Kronig analysis of infrared reflectance spectra. Physica B 2016, 499, 38-43. [CrossRef]

38. Kanatt, S.R.; Rao, M.S.; Chawla, S.P.; Sharma, A. Active chitosan-polyvinyl alcohol films with natural extracts. Food Hydrocolloid. 2012, 29, 290-297. [CrossRef]

39. Farris, S.; Introzzi, L.; Biagioni, P.T.; Holz, L. Piergiovanni, wetting of biopolymer coatings: Contact angle kinetics and image analysis investigation. Langmuir 2011, 27, 7563-7574. [CrossRef]

40. Raj, B.; Somashekar, R. Structure-property relation in polyvinyl alcohol/starch composites. J. Appl. Polym. Sci. 2004, 91, 630-635. [CrossRef]

41. Kubo, S.; Kadla, J.F. The formation of strong intermolecular interactions in immiscible blends of poly(vinyl alcohol) (PVA) and lignin. Biomacromolecules 2003, 4, 561-567. [CrossRef]

42. Fernandez-Saiz, P.; Ocio, M.J.; Lagaron, J.M. Antibacterial chitosan-based blends with ethylene-vinyl alcohol copolymer. Carbohydr. Polym. 2010, 80, 874-884. [CrossRef]

43. Bonilla, J.; Fortunati, E.; Atarés, L.; Chiralt, A.; Kenny, J.M. Physical, structural and antimicrobial properties of poly vinyl alcohol-chitosan biodegradable films. Food Hydrocolloid. 2014, 35, 463-470. [CrossRef]

44. Wang, D.L.; Lv, R.L.; Ma, X.B.; Zou, M.M.; Wang, W.J.; Yan, L.; Ding, T.; Ye, X.Q.; Liu, D.H. Lysozyme immobilization on the calcium alginate film under sonication: Development of an antimicrobial film. Food Hydrocolloid. 2018, 83, 1-8. [CrossRef]

45. Liu, X.X.; Chen, X.F.; Ren, J.L.; Chang, M.M.; He, B.; Zhang, C.H. Effects of nano-ZnO and nano-SiO 2 particles on properties of PVA/xylan composite films. Int. J. Biol. Macromol. 2019, 132, 978-986. [CrossRef]

46. Abrala, H.; Hartonoa, A.; Hafizulhaqa, F.; Handayanib, D.; Sugiartic, E.; Pradiptad, O. Characterization of $\mathrm{PVA} /$ cassava starch biocomposites fabricated with and without sonication using bacterial cellulose fiber loadings. Carbohydr. Polym. 2019, 206, 593-601. [CrossRef] [PubMed]

47. Alexy, P.; Bakoš, D.; Crkoňová, G.; Kramárová, Z.; Hoffmann, J.; Julinová, M.; Chiellini, E.; Cinelli, P. Poly(vinyl alcohol)-collagen hydrolysate thermoplastic blends: II. Water penetration and biodegradability of melt extruded films. Polym. Test. 2003, 22, 811-818. [CrossRef]

48. Yu, Q.; Song, Y.; Shi, X.; Xu, C.; Bin, Y. Preparation and properties of chitosan derivative/poly(vinyl alcohol) blend film crosslinked with glutaraldehyde. Carbohydr. Polym. 2011, 84, 465-470. [CrossRef]

49. Liu, H.H.; Adhikari, R.; Guo, Q.; Adhikari, B. Preparation and characterization of glycerol plasticized (high-amylose) starch-chitosan films. J. Food Eng. 2013, 116, 588-597. [CrossRef]

50. Huang, M.; Liu, Z.; Li, A.; Yang, H. Dual functionality of a graft starch flocculant: Flocculation and antibacterial performance. J. Environ. Manage. 2017, 196, 63-71. [CrossRef]

51. Ge, J.J.; Shi, X.H.; Cai, M.Q.; Wu, R.; Wang, M. A novel biodegradable antimicrobial PU foam from wattle tannin. J. Appl. Polym. Sci. 2003, 90, 2756-2763. [CrossRef]

(C) 2019 by the authors. Licensee MDPI, Basel, Switzerland. This article is an open access article distributed under the terms and conditions of the Creative Commons Attribution (CC BY) license (http://creativecommons.org/licenses/by/4.0/). 